\title{
Mathematical media literacy in the COVID-19 pandemic and its relation to school mathematics education
}

\author{
Einat Heyd-Metzuyanim ${ }^{1}$ (D) A Aviv J. Sharon ${ }^{1}$ (D) - Ayelet Baram-Tsabari ${ }^{1}$ (D)
}

Accepted: 24 May 2021 / Published online: 19 June 2021

(C) The Author(s), under exclusive licence to Springer Nature B.V. 2021

\begin{abstract}
In the first months of 2020, as the COVID-19 pandemic became a top concern worldwide, media coverage became full of information that demands mathematical literacy, or numeracy, to interpret. In this study, we examine the public's understanding of mathematical notions that are required for understanding the pandemic and predicting its spread. We also explore its correlations with several variables: age group and gender, educational attainment in mathematics, and mathematics identity. To do so, we conducted a cross-sectional survey focusing on mathematical knowledge relevant to the pandemic. The survey was distributed to a representative sample of the Jewish Israeli population $(n=$ 439). Findings showed that participants' educational attainment in mathematics was positively correlated with their success in the mathematical media literacy tasks. However, even those with high attainment levels did not always perform well. Moreover, the explanatory variable with the strongest relationship to mathematical media literacy was found to be participants' mathematical identity. These results suggest that school mathematics, especially in its high levels, may prepare adults to understand critical information important for their well-being, such as at a time of global pandemic. However, they also demonstrate that a weak mathematical identity may significantly hinder adults' engagement with such information.
\end{abstract}

Keywords Adult numeracy C COVID-19 Public understanding of science $\cdot$ Public understanding of mathematics · Mathematics identity $\cdot$ Attitudes towards mathematics $\cdot$ Mathematics in the news

One day at the beginning of February 2020, in the midst of the burgeoning public awareness of the rapid spread of COVID-19, the first and third authors held a collegial chat. The subject was masks, which the first author had just ordered online, a move that the third author thought was a bit of an over-reaction to somewhat distant news. "Well," said the first author, "I know what the beginning of an exponential function looks like," and with that, the conversation ended.

Einat Heyd-Metzuyanim einat.metz@gmail.com 
Several weeks later, when the pandemic was already rapidly spreading in the authors' country, and when masks, lockdown and quarantine were already a part of our daily lives, we looked back at that distant conversation and asked ourselves: did it really matter that the first author is a mathematics educator and highly sensitive to the mathematical aspects of the news about the pandemic? More generally, we wondered whether mathematics education enables people to understand the realities of their lives during this unprecedented global situation, and if so, how. Do people engage with the mathematics underlying the pandemic in the first place? Do they understand it? These questions have practical implications for the communication of quantitative information in the context of science and health, but they also have implications for mathematics education. For example, does school mathematics sufficiently prepare people to cope with math-laden situations in their lives? What elements seem to be important in this process - the level of mathematical knowledge gained in school? Is it the general "mathematical identity" that students get out of school mathematics (Boaler \& Selling, 2017; Graven \& Heyd-Metzuyanim, 2019)? In turn, the answers to these questions can inform the design of curricula, pedagogy, and assessment in mathematics education.

\section{Theoretical background}

Public understanding of mathematics is relatively under-researched, compared to public understanding of science. Most of the work on this issue in mathematics education comes from two strands of research: The first is adult numeracy (Coben, 2003; Evans, 2000; Gal et al., 2020; PIAAC Numeracy Expert Group, 2009), particularly with respect to health contexts (Ancker \& Kaufman, 2007) and statistics (Gal, 2002). The second derives from the efforts to enhance adult mathematical skills through measures such as the Program for the International Assessment of Adult Competencies (PIAAC) (OECD, 2016). Hence, for the purposes of our literature review, we will draw on studies of mathematics literacy and adult numeracy and then supplement it with insights from research on public engagement with science.

\subsection{Mathematical literacy among adults as it relates to COVID-19 news coverage in Israel}

The OECD Survey of Adult Skills (PIAAC; OECD, 2016; PIAAC Numeracy Expert Group, 2009) uses the term "numeracy" for conceptualizing the mathematical demands of adults in their daily lives or workplace. They define numeracy as:

the ability to access, use, interpret, and communicate mathematical information and ideas, in order to engage in and manage the mathematical demands of a range of situations in adult life (PIAAC Numeracy Expert Group, 2009, p. 21).

The PIAAC Numeracy Expert Group (2009) specifies the types of responses expected from a numerate (or mathematically literate) person, which include identifying, locating, or accessing mathematical information; acting upon or using this information; and interpreting, evaluating, and communicating numerical information. Of these three types of responses, the COVID-19 pandemic demands from most laypersons to interpret numerical situations as well as act upon them. They are expected to understand why 


\section{קורונה - כל העדכונים}

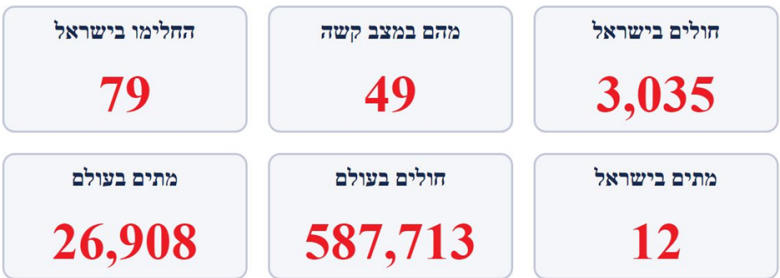

Fig. 1 A snapshot taken from Ynet - a popular news website — on March 27, 2020. The headline reads: COVID19 in Israel-Status report. The boxes from top right to bottom left read: Cases in Israel, of which in critical condition, recoveries in Israel, deaths in Israel, cases around the world, deaths around the world. Image reproduced with permission from Ynet

certain actions have been decided upon at a policy level, abide by these decisions, or critique them.

The PIAAC definition of numeracy (PIAAC Numeracy Expert Group, 2009) relates to the following mathematical domains: quantity and number; dimension and shape; pattern, relationships, and change; and data and chance. Of these four, the COVID-19 situation, as it was covered by the Israeli mainstream media during the first weeks of the pandemic, is related mainly to numbers and patterns of change. Counting numbers were (and still are) dominant in any report about the spread of the virus, seen, for example, in reports of numbers of confirmed cases, critically ill, deceased patients, etc. Figure 1 showcases a typical display in the public media of such numerical information, which for many days figured in the Israeli news on the front pages of news websites.

"Patterns and change" relate, in the PIAAC Numeracy Expert Group's (2009) words, to "the mathematics of how things in the world are associated or develop." These figured during the COVID-19 pandemic's first weeks mainly in the discourse around "exponential growth" and in its graphical counterpart slogan of "flattening the curve." A famous graphical representation circulating in social media and the news relating to this domain is captured in Fig. 2.

Interestingly, the domain of "data and chance" was conspicuously absent from the Israeli media discourse around the COVID-19 during the first few weeks. The main issue around which chance was discussed was case fatality rates and the chances that one would end up in a critical

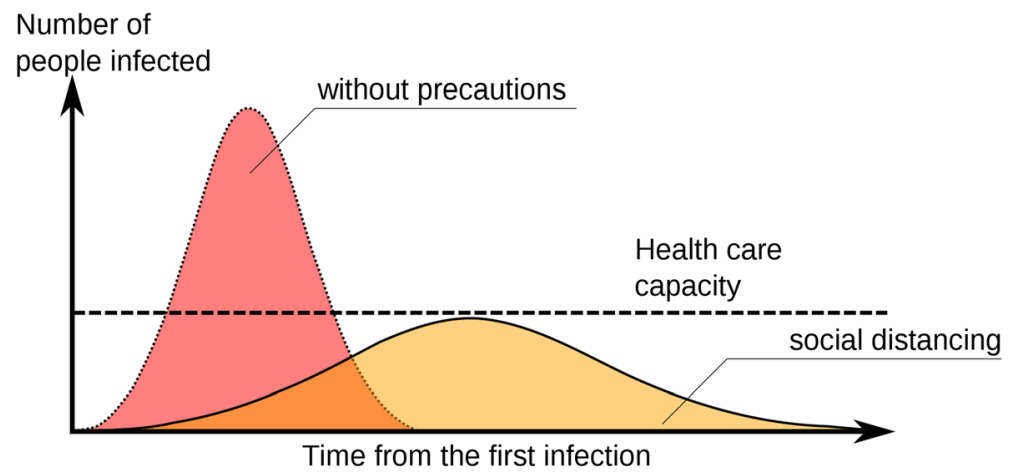

Fig. 2 A "flattening the curve" graph. From COVID-19 Health care limit, by Kalliauer (2020), Wikimedia Commons (https://commons.wikimedia.org/wiki/File:COVID-19_Health_care_limit.svg). Licensed under CCBY-SA-4.0 


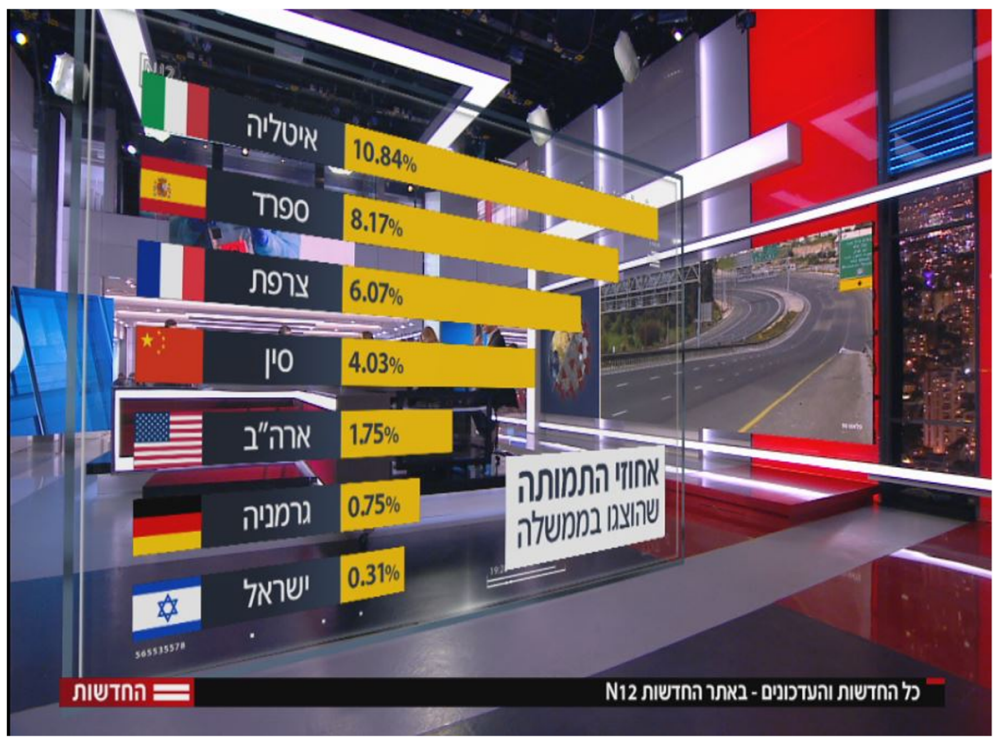

Fig. 3 Bar chart of mortality rates of COVID-19 by country, reportedly based on governmental data, presented on the Channel 12 News evening newscast in Israel, on March 29, 2020. According to Israel Audience Research Board data, this newscast was the most watched TV program on that day, reaching an estimated viewership of $12.5 \%$ of individuals ages 4 and up in Israel, (https://www.the 7eye.org.il/rating/367106). The country names and reported mortality rates, from top to bottom, are Italy $(10.84 \%)$, Spain $(8.17 \%)$, France $(6.07 \%)$, China $(4.03 \%)$, the USA $(1.75 \%)$, Germany $(0.75 \%)$, and Israel $(0.31 \%)$. Image reproduced with permission from the Israel Television News Company

condition or even dying given particular initial conditions. These were usually displayed in the form of percentages, for example, of mortality rates in different countries (see Fig. 3).

PIAAC is one of the main studies that can inform us about adult numeracy levels, testing 16-65 year-olds in 33 countries, including Israel (OECD, 2016; PIAAC Numeracy Expert Group, 2009). PIAAC divides proficiency in numeracy skills into 5 levels (1-5), where level 1 is the lowest and level 5 is the highest. According to the PIAAC report (OECD, 2016), tasks at level 2 were mastered by $30.4 \%$ of the tested population $\left(30.1 \%\right.$ among Jewish Israeli adults ${ }^{1}$, Israel Central Bureau of Statistics and National Authority for Measurement and Evaluation in Education, 2016, pp. 158, 160). These tasks "require the respondent to identify and act on mathematical information and ideas embedded in a range of common contexts where the mathematics content is fairly explicit or visual with relatively few distractors" (OECD, 2016; p. 48). Tasks at level 3, mastered by $26 \%$ of the adult population (30.1\% among Jewish Israeli adults), "require the respondent to understand mathematical information that may be less explicit, embedded in contexts that are not always familiar and represented in more complex ways. Tasks require several steps and may involve the choice of problem-solving strategies and relevant processes" (ibid). Although we do not have access to the exact ways by which PIAAC categorizes tasks to different levels, we assume that most of the tasks related to the interpretation of COVID-19 news fall under levels 2 or 3 . This assumption is based on the tasks shown below: the mathematics content in them is usually "fairly explicit or visual" (level 2), yet the pandemic situation may be unfamiliar to most people, meaning the mathematics may be "embedded in contexts that are not always familiar" (level 3).

\footnotetext{
${ }^{1}$ We report the results from the Jewish segment of the Israeli population to match the sample of the current study
} 
To gain a deeper view of adults' proficiency in domains of numeracy, we will now review some studies done on content areas that were identified above as central for understanding the mathematical aspects of the COVID-19 pandemic.

\subsection{Adult proficiency in sub-domains of mathematics}

\subsubsection{Basic calculations}

Studies of basic calculations at the level usually learnt in the lower grades of elementary school are relatively rare. Maaß and Schlöglmann's (2000) findings suggest that adults generally have good command of mathematical knowledge acquired in the first 5 years of school, such as calculating with small integers, as opposed to decimal numbers, fractions, or percentages or performing complicated calculation procedures (cited in Ehmke et al., 2005). We do not, however, have information about the characteristics of their sample.

Studies of adults' command of mathematics in general, and elementary mathematics in particular, often reveal differences between adults with basic mathematics education (that which is considered mandatory in schools in their country) and advanced mathematics (courses taken as elective at high school or beyond) (Karsenty, 2004; Maffia \& Marrioti, 2018). For example, Maffia and Mariotti (2018) qualitatively examined adults' mastery of times tables facts and computational strategies of multiplication. They found that interviewees with relatively advanced mathematics education showed better abilities at what they termed "the meta-cognitive dimension" (p. 105), changing their approach to calculation flexibly according to the required multiplicative fact. In contrast, interviewees with low-level mathematical education used rigid scripts for multiplicative situations and were "not able to associate the mathematics they learnt inside the school's walls to everyday life contexts" (p. 106).

\subsubsection{Statistical reasoning}

Mathematical skills of adults in domains that are learned at middle school and high school levels have been studied mostly with relation to statistics, particularly in the context of health numeracy and assessments of risk (Ancker \& Kaufman, 2007; Golbeck et al., 2005). For example, Schwartz et al. (1997) assessed the extent to which women accurately assessed the benefits of screening mammography based on different representations of risk reduction. They found that women's accuracy in applying risk reduction information was generally poor and was strongly related to their numeracy, as measured by de-contextualized tasks.

\subsubsection{Understanding graphs}

Other studies examined the extent to which probability information is accessible through various graphical representations (Ancker et al., 2006). These studies showed that the extent to which patients correctly assess the risk associated with certain health-related behaviors (such as smoking) greatly varies in relation to what aspects are highlighted by the graphical representations and is strongly related to previous familiarity and expertise with specific graphical formats, mostly obtained via mathematics or science schooling (Ancker et al., 2006). 


\subsubsection{Other topics}

Few studies of adults' proficiency in mathematics are related specifically to other mathematical content areas, studied in middle or high school, which are relevant to the COVID-19 pandemic. These include adults' memory of linear functions (Karsenty, 2002) and calculus (Gyllenhaal, 2006). Both these studies found that adults' memory of mathematical concepts and procedures learned in high school was usually very fragmented, unless they revisited these subjects through later mathematical studies.

One of the major mathematical topics, which stood at the heart of much of the public reporting on the COVID-19 pandemic, is that of linear vs. exponential growth. There is a significant body of research showing that the differentiation between these two types of growth is a major challenge both to school students and adults (e.g., Ebersbach et al., 2008; Van Dooren et al., 2008; Wagenaar \& Sagaria, 1975). These studies show that people often have difficulties understanding and forecasting processes based on exponential functions. Moreover, students often have a strong tendency to over-generalize linear phenomena to non-linear processes (De Bock et al., 1998). These over-generalizations are related to people's tendency to take the differences between the single steps of exponential processes into account rather than focusing on the process as a whole. This results in implementation of strategies that are appropriate for a constant rate of change, rather than considering the non-constant rate of change in exponential (or other non-linear) growth (Ebersbach et al., 2008). Recently, Podkul et al. (2020) reported findings from a survey concerning US adults' understanding of linear versus exponential growth. They found that the majority of respondents $(73 \%)$ could correctly predict the number of patients after 10 days with a simple linear progression ( +10 each day), yet $90 \%$ underestimated the number of diagnosed people in an exponential growth situation (10 infected by each person for a total of $10^{10}$ at the end of 10 days).

\subsection{Affective aspects of adult numeracy}

Much empirical evidence points to the importance of affect for successful mathematical learning and to the reciprocal relationships between attitudes and achievements in mathematics (Aiken \& Dreger, 1961; Ma \& Kishor, 1997; McLeod, 1992). However, studies of adults' attitudes or emotions towards mathematics are relatively rare (Evans, 2000; Johnston-Wilder et al., 2014; Karsenty, 2004; Wedege \& Evans, 2006). These studies point to differences between men and women in their affective relationship towards mathematics, where men feel more confident about mathematics, although these differences interact with socio-economic status (Evans, 2000).

Evans (2000) found mathematics anxiety to be inversely related to performance of both school math problems and practical math problems, in a sample of 935 adult students in a polytechnic institution. Gal (2002) suggested that dispositional elements, including beliefs, attitudes, and critical stance are an essential aspect of "statistical literacy" (p. 4).

To capture these broad dispositional elements, in this study we use the term "mathematical identity." This term has been used to capture the broad spectrum of non-cognitive relations of people to mathematics, including their attitudes towards the subject, their stories about themselves as mathematics doers, and their beliefs about mathematics (Bishop, 2012; Boaler \& Selling, 2017; Darragh, 2016; Graven \& Heyd-Metzuyanim, 2019). We define mathematical identity as the set of stories a person tells about herself as a learner and doer of mathematics (Heyd-Metzuyanim, 2015; Sfard \& Prusak, 2005). These stories can be quite 
complicated and multi-voiced, drawing on the surrounding culture and impacted by thirdperson stories (what others, such as teachers, say about her math ability), and not just stories in the first person. However, for the purpose of the present study, which will make use of surveybased self-reports, we operationalize mathematical identity as a set of culturally available narratives (such as "I am good in math") that a person endorses about herself to describe her affective relation to mathematics and her history as a mathematics learner.

There are strong reasons to believe that the mathematical identity formed at school impacts adults' engagement with mathematics later in life. For example, Boaler and Selling (2017) followed students who were found to have constructed different mathematical identities during high school, as a result of different teaching approaches ("traditional" vs. project-based), and found that 8 years later, there were strong relations between the math identity formed in school and the ways by which young adults relate mathematics in their lives.

The literature reviewed so far on mathematical literacy, numeracy, and competence of adults rarely relates to mathematics as it appears in the public media, signaling that the field of "public engagement with mathematics," unlike the field of "public engagement with science," may be in is nascent form. We therefore draw on the relatively wider knowledge gained about these issues in the domain of public engagement with science.

\subsection{Science literacy and mathematical media literacy}

In recent decades, the primary goal of science education has been to prepare non-scientists to make sense of science in their daily lives, to be critical consumers of science information, and to make informed decisions about scientific issues (Roberts \& Bybee, 2014). A similar goal has led mathematics education (Niss, 1996).

The literature reports cases in which science literacy manifests itself in adult life and helps laypeople achieve various goals, including becoming more effective caregivers or patients (e.g., Shauli \& Baram-Tsabari, 2019; Weeth Feinstein, 2014). One thread of studies which is particularly relevant for the present study relates to "science media literacy" (Jarman \& McClune, 2007, as cited in Fives et al., 2014) or "scientific media literacy" (Reid \& Norris, 2016, p. 152), which relates to public engagement with science in the media (e.g., Laslo \& Baram-Tsabari, 2021; McClune \& Jarman, 2010; Reid \& Norris, 2016). By and large, this thread of research suggests that there are serious limitations in the public's ability to critically evaluate science-related information presented in the media (e.g., Nordheim et al., 2019; Tseng, 2018). These studies, however, have not related specifically to mathematical issues. Here we propose the term "mathematical media literacy" and define it as the ability to correctly interpret numeric information presented in the news media.

\section{Research objective and questions}

Understanding and interpreting media reports correctly is crucial at a time of a global health threat. Our research objective, therefore, is to discover the extent of mathematical media literacy relating to the COVID-19 pandemic, and to determine the extent to which people's formal schooling and mathematical identity correlate with this.

Two research questions guided this study: 
1. To what extent do individuals correctly interpret COVID-19-related mathematical information featuring in the media?

2. To what extent do formal schooling, mathematical identity and demographic variables correlate with the ability to interpret mathematical information relevant to the pandemic?

\section{Methods}

This empirical and quantitative investigation used questionnaires administered to a representative sample of Jewish Israelis to study their interpretation of math contents in authentic COVID-related news, alongside mathematical identity (hereafter: math identity) and educational and general demographics.

\subsection{Context of the study-COVID-19 in Israel}

The study was conducted in Israel during March-April 2020. Israel saw its first confirmed COVID-19 case on February 21st. During the first 2 weeks of March, the Israeli government initiated growing measures of social distancing, to the point of a full lockdown by March 17th. The number of confirmed cases quickly rose during the last week of March, to 6092 confirmed cases by April 1st. During the first 2 weeks of April, when the data collection took place, most Israelis were in lockdown and the rate of growth in confirmed cases declined substantially, from 14 to $4 \%$ (Data source: Israel Ministry of Health).

During the first weeks of the pandemic, and especially during lockdown, the Israeli newscasts were overwhelmingly focused on the virus, its spread, and the measures the government was taking against it. The Israeli prime minister and other government officials gave live televised speeches almost every evening, declaring the latest restrictions. This "state of public emergency" is the background of our study.

\subsection{Research tools}

\subsubsection{The mathematical media literacy questionnaire}

We designed the questionnaire to assess whether participants correctly interpreted mathematical information presented in the public media at the time of study. We searched the news media and public media for items that contained mathematical information by web-searching, surveying the main Israeli print and broadcast (TV) news websites (ynet.co.il, n12.co.il, maariv.co.il, haaretz.co.il), as well as collecting relevant viral posts from Facebook.

The twenty-one (21) items were designed to assess interpretations of as many mathematical topics that we could find in the national media at the time. These included differentiating between linear, polynomial, and exponential growth; understanding the meaning of exponents; reading bar graphs; interpreting the "flatten the curve" graphs; and interpreting the relation of an exponent to the rate of change. In certain questions, such as the item requesting to differentiate between linear and exponential growth, we included "contextualized" vs. "de-contextualized" items, which we designed to assess, more or less, the same mathematical knowledge with and without context related to the COVID-19 pandemic. For example, item Q53 (see Table 1 for all items) started with an 


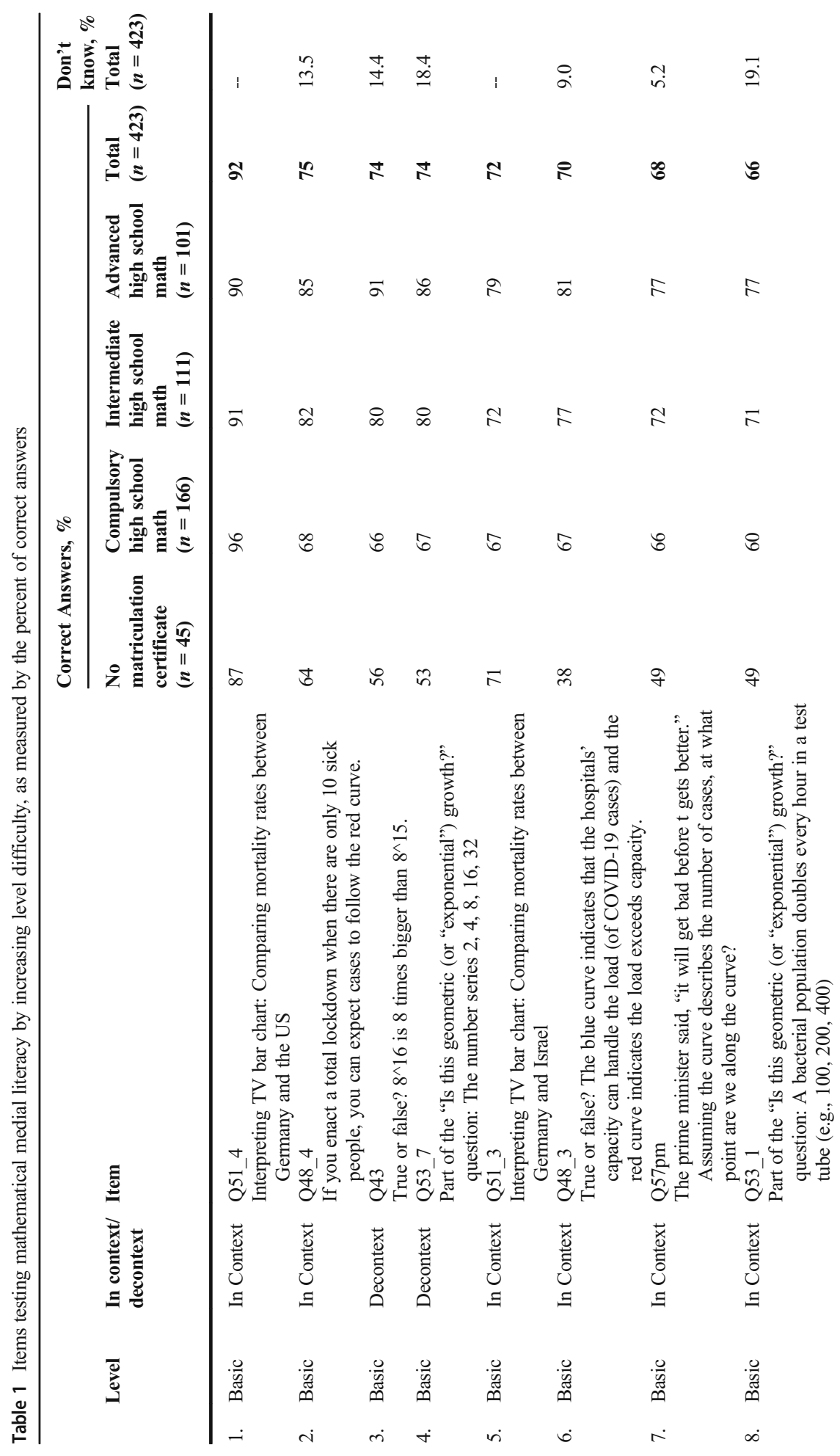




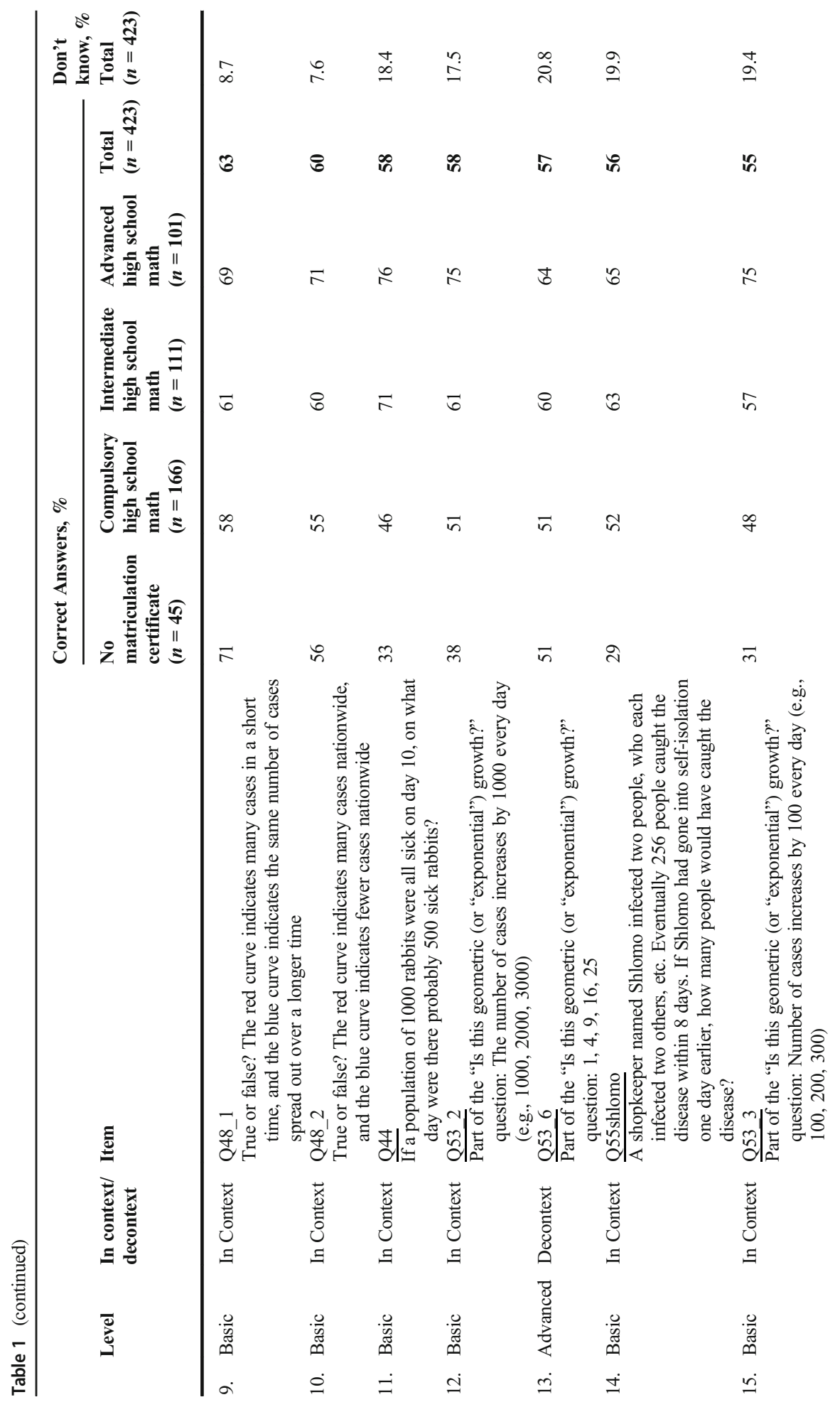




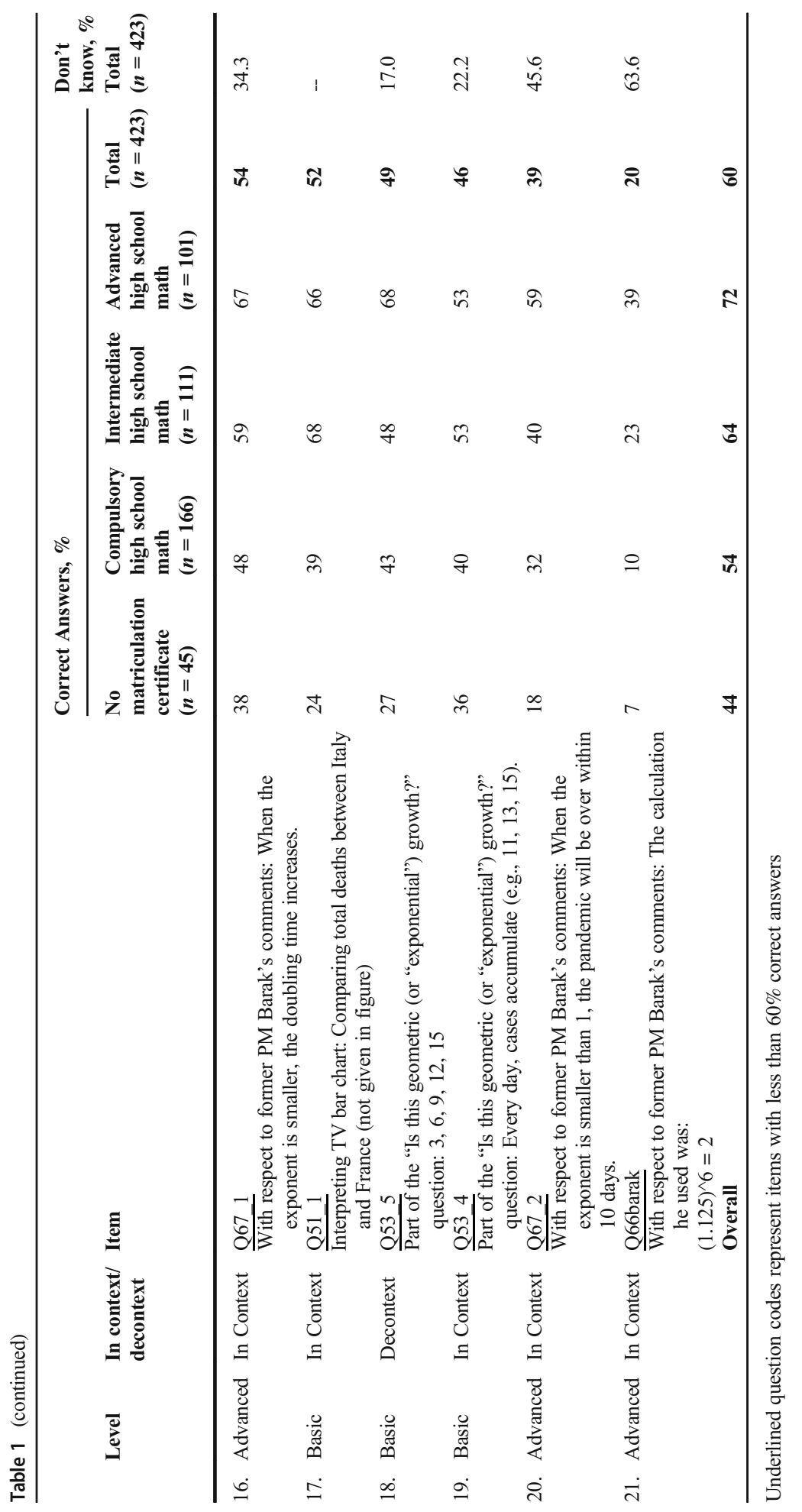


explanation of exponential growth, as explained by the Israeli Prime Minister on prime time TV news. The stem of the question read:

The prime minister said that the coronavirus is spreading in a geometric sequence. 'One person infects two, each one infects two more, the four infect eight, the eight 16 and so forth... The rate of infection is not constant. It starts as if it is constant, but ascends quickly to enormous heights.'

Following this quote, the question stated: "of the following situations, mark if they describe a geometric sequence (or 'exponential growth') or not." This was followed by seven statements. These included four contextualized scenarios such as "the total number of confirmed cases grows by a 1000 each day (for example, a total of 1000 on Sunday, 2000 on Monday, 3000 on Tuesday, etc.)" and three decontextualized sequences including " $3,6,9,12,15$ "; " $2,4,8,16$, 32 "; and " $1,4,9,16,25$."

The items were divided into "basic" and "advanced" levels of mathematical knowledge with the help of a panel of five experts (see explanation below). Additionally, the items were divided into items directly related to COVID-19 ("contextualized") and items that are decontextualized, using the same method (see Online Resource 3).

Determining the level of mathematical knowledge needed for answering items and whether they are contextualized to COVID-19 Our questionnaire was built in a bottomup fashion, extracting mathematical topics from the authentic news items, rather than a top-down fashion where the topics would be predetermined and then tasks would be designed around the topics. For this reason, we had no pre-determined ordering of the items according to the school curriculum. We thus asked an expert panel of five mathematics educators to categorize the questions to mathematical knowledge learned at (1) a basic level, containing knowledge learned in elementary, middle school, and the compulsory-level matriculation mathematics (named the 3-unit matriculation level in the Israeli system; for example, item Q51_3, which required interpreting a bar chart) (17 items) and (2) an advanced level, mathematics learned only at intermediate or advanced high school levels (named the 4- or 5-unit matriculation levels, respectively; this level contained 4 items, for example, item Q67_2, which required plugging values into an exponential function). The panel consisted of five graduate students in education, with mathematics teaching experience ranging from 4 to 17 years. Blind agreement was $82 \%$.

The experts were also asked to assess whether the item was provided within a COVID-19related context (17 items) or de-contextualized (4 items). Here, blind agreement was $98 \%$.

Participants' mathematical media literacy scores For each correct answer, a respondent received the value of " 1 " on a corresponding score; otherwise, the value of the score was 0 . Next, the values of the scores were averaged together to provide indices for the basic level items (17 items), for the advanced level items (4 items) and for all items (21 items). The values of the indices were then multiplied by 100 . Thus, we show grades (hereafter "mathematical media literacy scores" or "math scores") calculated for each participant on a percent scale ranging between 0 and 100. Cronbach's alpha values were high for the overall index (.86.) and for the basic level index (.83) but borderline for the advanced level index (.57). 
The mathematical identity scale We devised a 10-item scale designed to assess 5 elements: (a) participants' description of themselves as doers of mathematics (e.g., "I am good at math"); (b) their description of their emotional relationship with mathematics (e.g., "I like math"); (c) their interest in mathematics ("math interests me"); (d) their perceptions of themselves as able to learn math (e.g., "I know the multiplication table by heart"); and (e) their perception of mathematics as a useful subject (e.g., "math is a subject that is unrelated to real life," reverse coded; Table 2). Respondents were asked to rate their agreement with the propositions on a Likert scale ranging between 1 ("not at all") and 5 ("very much"). A score for each respondent was calculated by averaging item responses, after recoding the inverse items. The index was highly internally consistent (Cronbach's alpha $=.86$ ). For further details about this scale, see Online Resource 3.

The mathematical identity scale drew on items from established questionnaires (Table 2). For example, the Mathematics Attitudes and Anxiety Questionnaire (MAAQ; Dowker et al., 2012), designed for young children, includes descriptions of oneself as a doer of mathematics and one's emotional relationship with mathematics. Similarly, the TIMSS 2019 Context Questionnaire (Mullis \& Martin, 2017) includes (1) items reflecting the self as a doer of mathematics, such as "I usually do well in mathematics"; (2) items using emotional language, such as "Mathematics makes me nervous" and "confused"; (3) items reflecting perceptions of interest, such as "Mathematics is boring"; and (4) items reflecting perceptions of usefulness, such as "I think learning mathematics will help me in my daily life."

Demographic variables Measured demographic variables included self-reports of gender, age group, place of residence (measured as telephone dial codes), occupation, income level, highest level of completed formal education, and level of formal schooling in mathematics, all as multiple-choice items.

The level of formal schooling in mathematics was measured using the level of math taken in the matriculation exams when finishing high school (hereafter levels of "high school math"; See details in Online Resource 3). Here the options included:

Table 2 The mathematics identity scale and equivalent items in established questionnaires

Item Equivalent items

1. I like math.

2. Math is necessary for understanding the world around us.

3. I am good at math.

4. Math was my most-hated subject.

5. Math interests me.

6. There are topics in math that I never managed to learn even though I tried.

7. I know the multiplication table by heart.

8. Math is not my strong suit.

9. Math is a boring subject.

10. Math is unrelated to real life.
"How much do you like" different domains of mathematics (MAAQ)

Opposite to 10 (TIMSS)

"How good are you?" at different domains of mathematics (MAAQ); "I usually do well in mathematics" (TIMSS)

Opposite to 1

Opposite to 9

Original (Refers to history as a math learner)

Original (Refers to history as a math learner); Opposite to 6 Opposite to 3

"Mathematics is boring" (TIMSS)

"I think learning mathematics will help me in my daily life" (TIMSS)

MAAQ: Mathematics Attitudes and Anxiety Questionnaire (Dowker et al., 2012). TIMSS: Trends in International Mathematics and Science Study (Mullis \& Martin, 2017) 
(1) Not completing any matriculation exam in mathematics ("No Matriculation")

(2) “Compulsory" High School Math (3 study units)

(3) "Intermediate" High School Math (4 study units)

(4) "Advanced" High School Math (5 study units)

Additionally, to facilitate the analysis, the age groups were collapsed into a dichotomous measure as either 18-29 (young adults) or 30-70 (older adults). We used age 30 as a cutoff point because the survey data for age groups in the 30-70 range appeared similar upon close inspection and differed from the data for younger adults.

Other questions Additional variables included participants' risk perceptions of the COVID-19 pandemic, their sense of control during the crisis, their decision-making in the context of the pandemic, and the argumentation they used to justify their decisionmaking. The data collected from this part of the questionnaire were not analyzed for this study.

\subsection{Pilot testing}

A pilot version was tested among a sample of 31 respondents purposely sampled for maximum variation in level of mathematical education. Cognitive interviews were conducted to assess the clarity of questions and the thinking processes involved in solving the tasks, to confirm that the items were understood as intended. The questionnaire was subsequently modified for clarity based on initial feedback. However, due to the need to deploy the questionnaire quickly (to capture the time where COVID-19 news was initially spreading), cognitive interviews were not systematically analyzed. Thus, the issue of whether these items capture precisely the mathematical knowledge that we aimed to assess remains for further qualitative investigation.

\subsection{Data collection}

We conducted an online cross-sectional survey, asking respondents to provide demographic data, rate their agreement with items regarding their mathematics identity, and solve mathematical problems in the context of the COVID-19 pandemic.

Participants were recruited by a market research firm from an online panel representative of Hebrew-speaking Israeli internet users between ages 18 and 70. First, a sample of approximately 7050 individuals was drawn from a proprietary database of Internet users previously recruited by the firm. Stratified sampling was used to ensure representation of different groups by gender, age group, level of completed education, and religiosity. This sample received e-mail invitations to participate in the study, and 1147 participated elected to take part, yielding a $16.3 \%$ response rate. Then, among these participants, quota sampling was employed by automatically terminating the questionnaire for participants who reported that they belonged to groups that were sufficiently represented in the sample. For example, after 300 respondents who indicated they had completed tertiary education, any further respondents who indicated that they had done the same were automatically rejected from the sample. Statistics about the representativeness of the sample can be found in Online Resource 1. Each participant 
who completed the questionnaire was compensated by the market research firm with credit towards a gift card.

The survey was launched on April 2nd and closed on April 12, 2020. The sample included 439 complete questionnaires that were used in the analysis. The median time of completion of the questionnaire was $15.73 \mathrm{~min}$ (Inter-quartile range: $10.53 \mathrm{~min}$ ). The study was reviewed and approved by the Institutional Review Board at the TechnionIsrael Institute of Technology (Approval \#2020-032).

\subsection{Statistical analysis}

To answer RQ1, regarding correct interpretations of COVID-19 related quantitative information, we calculated the percent of correct answers for each item and tabulated the items in increasing order of difficulty. We then computed each participant's average success rates for several contextualized and de-contextualized items and conducted a Wilcoxon signed-rank test to assess whether the population means differed. For further details about this statistical analysis, see Online Resource 3.

To answer RQ2, regarding the correlations of formal schooling, math identity, and demographic variables with ability to interpret COVID-19 quantitative information, we performed the following: First, we computed a Spearman's rank correlation coefficient to determine whether the participants' high school math levels correlated with their overall mathematical media literacy scores. Then, we conducted one-way ANOVAs to determine if there were differences in mathematical media literacy scores between groups with different levels of formal schooling in mathematics ("high school math levels").

Subsequently, to further investigate the relative contribution of formal schooling to mathematical media literacy scores while controlling for three additional variables, we conducted a general linear model with additional explanatory variables: math identity, time to complete the survey, gender, and age group. We also tested several interactions between these variables. For further details about this statistical analysis, see Online Resource 3.

\subsection{Methodological limitations}

Several limitations should be considered when interpreting the results. First, this is a crosssectional survey, which allows for documenting correlational relationships between variables such as educational attainment and mathematical media literacy but cannot answer questions of causation.

Second, since this is a new instrument, it would be easier to derive valid inferences from its results if there were comparisons conducted between its scores and those of other scales, such as the Survey of Adult Skills (PIAAC; OECD, 2019).

Third, as this was an online survey, we could not ensure that the conditions of application of the survey were the same across all participants.

Fourth, regarding our sample: Women are underrepresented in the sample, which might be indicative of self-selection of women to opt out of the survey due to its mathematical content. Similarly, participants without matriculation certificates were underrepresented in the sample, and people with tertiary education were overrepresented.

Fifth, we surveyed only internet users. Since internet use is relatively less common among Haredim (Ultra-Orthodox Jews), this could explain why this population was under-represented (see Online Resource 1 for differences between our sample and demographics of the 
population). Boys and men in this population typically attend educational institutions whose curriculum does not emphasize mathematics. All these sampling limitations may imply an overestimation of mathematical media literacy.

Sixth, many variables that may have had explanatory power were not measured, such as media consumption habits, levels of curiosity and anxiety, risk perceptions, and more.

Notwithstanding these limitations, this study affords a unique opportunity to study the public understanding of mathematical content in relation to one's formal mathematics education in the context of authentic media presented at the time of the survey.

\section{Findings}

\subsection{RQ1: To what extent do individuals correctly interpret COVID-19-related quantitative information featuring in the media?}

If the mathematical media literacy survey was an exam and the threshold for passing was 55 percentage points, our sample of the Jewish adults in Israel would have passed the "mathematical media literacy exam" - but only barely. The average "grade" (proportion of correct answers) on the overall math knowledge questionnaire was between 59 and 60 percentage points $(S D 23.5)$. The average "grade" was 64 points on the subset of compulsory math items ( $S D$ 23.9) and 42 points on the subset of advanced knowledge items ( $S D$ 31.2; Table 3).

All 21 items appear in Table 1 in descending order of correct answers, that is, from the highest success rate to the lowest. In general, we see a correspondence of the "basic" vs. "advanced" categories, as determined by experts, with our sample's success rate on these items. Thus, all items with average and above-average success rates (Table 1, rows 1-10) demand basic high school mathematics, while those that demand advanced high school mathematics have below-average success rates (rows 13, 16, 20, and 21).

The findings indicate that our sample was mostly successful in interpreting the common graphs associated with the pandemic, including charts of death rates (Table 1,

Table 3 Means and standard deviations for mathematical media literacy scores by participants' level of high school math

\begin{tabular}{|c|c|c|c|c|c|c|}
\hline & & \multicolumn{5}{|c|}{$\begin{array}{l}\text { "How many study units in mathematics did you take for your high } \\
\text { school matriculation certificate?" (Range: } 3,4 \text { or } 5 \text { ) }\end{array}$} \\
\hline \multirow{6}{*}{$\begin{array}{l}\mathrm{n} \\
\mathrm{n}(\% \text { of total) } \\
\text { Mathematical } \\
\quad \text { media }\end{array}$} & & $\begin{array}{l}\text { No } \\
\text { matriculation } \\
\text { certificate }\end{array}$ & $\begin{array}{l}\text { Compulsory } \\
\text { high school } \\
\text { math ( } 3 \\
\text { study units) }\end{array}$ & $\begin{array}{l}\text { Intermediate } \\
\text { high school } \\
\text { math (4 } \\
\text { study units) }\end{array}$ & $\begin{array}{l}\text { Advanced } \\
\text { high school } \\
\text { math (5 } \\
\text { study units) }\end{array}$ & Total \\
\hline & & 45 & 166 & 111 & 101 & 423 \\
\hline & & 11 & 39 & 26 & 24 & 100 \\
\hline & $\begin{array}{l}\text { Compulsory } \\
\text { items } \\
(n=17)\end{array}$ & $47.7(23.3)$ & $58.2(22.7)$ & $68.7(21.1)$ & $75.8(22.2)$ & $64.0(23.9)$ \\
\hline & $\begin{array}{l}\text { Advanced } \\
\text { items } \\
\quad(n=4)\end{array}$ & $28.3(27.5)$ & $35.1(28.6)$ & $45.5(30.6)$ & $57.4(31.3)$ & $42.4(31.2)$ \\
\hline & $\begin{array}{l}\text { Overall } \\
\qquad(n=21)\end{array}$ & $44.0(22.8)$ & 53.8 (21.7) & $64.3(20.8)$ & $72.3(22.4)$ & $59.9(23.5)$ \\
\hline
\end{tabular}


row 1) and the "flatten the curve" graph (Table 1, row 2; Fig. 2). On the latter item, however, the average performance of participants with no matriculation or compulsory high school math level was relatively low at 64 and $68 \%$, respectively, compared with the performance of participants who had intermediate or advanced high-school mathematics education ( 82 and $85 \%$, respectively).

The high score on the statement (Table 1, row 2) "If you enact a total lockdown when there are only 10 sick people, you can expect cases to follow the red curve," where $75 \%$ of participants interpreted this statement as wrong, is notable because it demanded some inclusion of information and logic not specified in the graph (see graph in Fig. 2). Thus, it demanded understanding that enacting total lockdown early on would slow the spread of the pandemic, leading to a flattened curve. It may be that this high incidence of correct interpretation was a result of the messages about "flattening the curve" being very prominent at the time in the media.

Interestingly, the participants scored relatively low on some questions that were determined by our experts' panel to demand only basic mathematics. In some cases, the scores on "basic" items were even lower than those on some "advanced" questions. These include two questions about one of the main issues at the center of the COVID-19 pandemic: linear versus exponential growth. Only $49 \%$ of our sample correctly indicated the sequence 3, 6, 9, 12, 15 is not an exponential sequence and only $46 \%$ correctly indicated that if each day infected people are added such that there is a total of 11, 13, 15 confirmed cases (growing by 2 each day), this, too, is not exponential growth. This was observed despite our experts' panel assessing the knowledge needed for these items to be learned at the level of compulsory mathematics.

Another question that received high rates of failure is asked for an interpretation of a graph showing death rates (in percentages) across different countries (see Fig. 3). A remarkable 48\% of respondents erred here, agreeing with the statement that Italy had in total more deaths from the virus than France, while this was not given in the graph (only death rates were given). Interestingly, all other items relating to this graph scored much higher. Yet, they did not demand differentiating between percentages and total numbers, nor did they demand extra information (such as total numbers of citizens) not presented in the graph.

We were also interested to see whether there was any difference between scores on items that were directly related to the COVID-19 situation (contextualized items) compared with scores on de-contextualized items. The results were inconclusive with no statistically significant difference between the scores on the in-context items $(M d n=50)$ and those on the decontextualized items $(M d n=66.7)$. This is evidenced by a Wilcoxon signed-rank test that we conducted to compare the differences within each participant's average math scores for the incontext items in Q53 (four items) and for the de-contextualized items in Q53 (three items; $z=$ $1.92, p=0.055)$.

\subsection{RQ2: To what extent do formal schooling, mathematics identity, and demographic variables correlate with the ability to interpret mathematical information relevant to the pandemic?}

On average, as the level of formal math education increased, so did mathematical media literacy with respect to COVID-19-related news (Table 3). This is evidenced by a statistically significant, moderate positive Spearman's rank correlation between the participants' high school math level and their overall mathematical media literacy scores, with an explained 


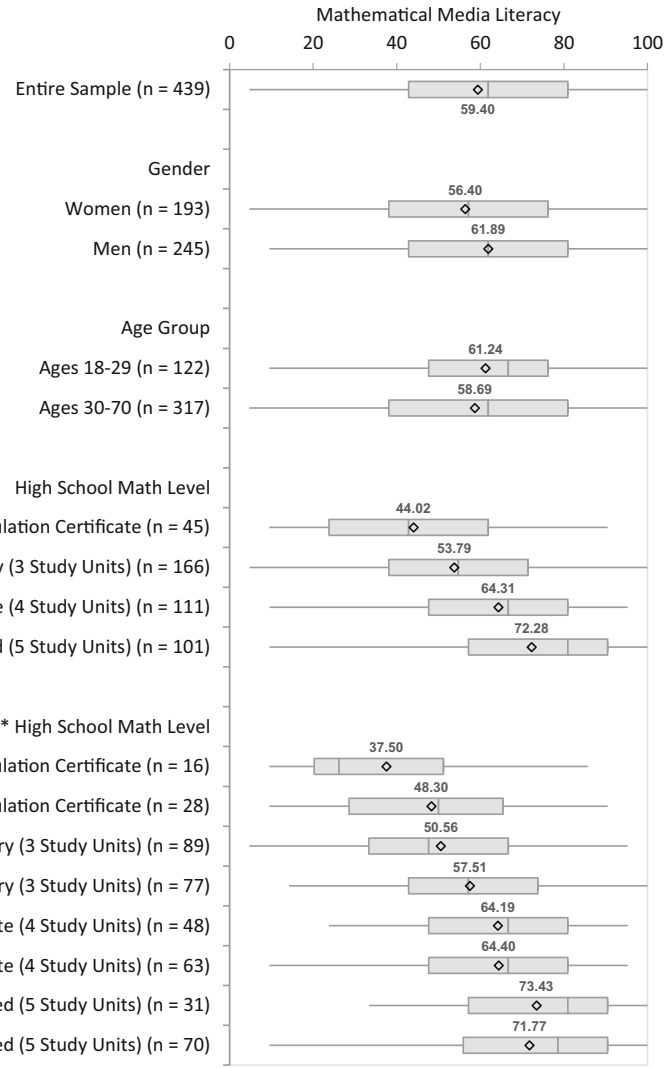

b

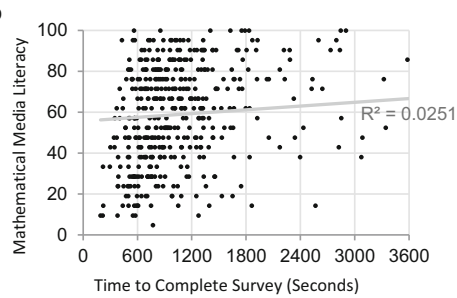

C

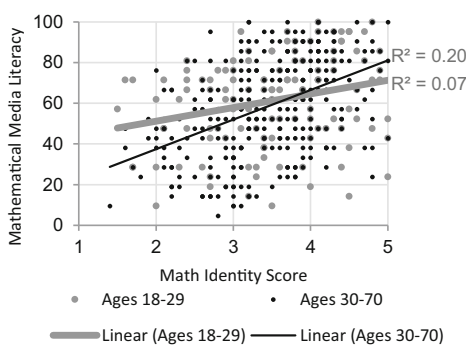

Fig. 4 (a) Mathematical media literacy by gender, age group, and high school math level. Whiskers extend to minimum and maximum values. (b) Mathematical media literacy by time to complete survey. (c) Mathematical media literacy by math identity and age group

variance of $15 \%$ between the ranked variables $\left(r_{s}=.39, p<0.001\right)$. This correlation was observed without controlling for demographics and other variables.

Additionally, a one-way ANOVA revealed that there are significant differences between the groups of participants that studied math at different levels in school (including Compulsory, Intermediate and Advanced levels in high school and those that did not obtain a matriculation certificate at all $),(F(3,419)=24.759, p<.001)$. The participants' level of high school math explained $15 \%$ of the variance in scores of mathematical media literacy $\left(\eta^{2}=\right.$ .151). Tukey post hoc analysis revealed that the mean increases between all groups were 
Table 4 General linear model analysis summary for respondent variables predicting mathematical media literacy $(n=421)$

\begin{tabular}{lllllll}
\hline Source & $\begin{array}{l}\text { Sum of } \\
\text { Squares }\end{array}$ & $d f$ & $\begin{array}{l}\text { Mean } \\
\text { Square }\end{array}$ & $F$ & $p$ & $\eta_{\mathrm{p}}{ }^{2}$ \\
\hline Corrected model & $5.835^{*}$ & 14 & .417 & 9.799 & $<.001$ & .253 \\
Intercept & 1.005 & 1 & 1.005 & 23.629 & $<.001$ & .055 \\
Gender & .120 & 1 & .120 & 2.832 & .093 & .007 \\
Age group & .289 & 1 & .289 & 6.797 & $\mathbf{. 0 0 9}$ & .016 \\
Attitudes towards mathematics & .913 & 1 & .913 & 21.463 & $<.001$ & .050 \\
Time to complete survey & .417 & 1 & .417 & 9.800 & $\mathbf{. 0 0 2}$ & .024 \\
High school math level & .272 & 3 & .091 & 2.135 & .095 & .016 \\
High school math level * Gender & .227 & 3 & .076 & 1.779 & .151 & .013 \\
Age group * Mathematics identity & .273 & 1 & .273 & 6.410 & $\mathbf{. 0 1 2}$ & .016 \\
High school math level * Mathematics identity & .137 & 3 & .046 & 1.072 & .361 & .008 \\
Error & 17.268 & 406 & .043 & & & \\
Total & 174.172 & 421 & & & & \\
Corrected total & 23.103 & 420 & & & & \\
\hline
\end{tabular}

$p$ values under .05 appear in bold. $* R^{2}=.253$

statistically significant, with three of the notable differences being between the No Matriculation group and the Compulsory group $(9.77,95 \%$ CI $[0.33,19.2], p=.039)$; between the Compulsory group and the Intermediate group $(10.52,95 \% C I[3.64,17.4], p=.001)$; and between the Intermediate group and the Advanced group (7.97, 95\% $C I[0.25,15.69], p=.04)$. This analysis, however, did not control for demographics and other variables.

We then turned to investigate whether additional variables would enhance our understanding of the phenomenon and increase the explained variance, namely: gender, educational attainment (Figure 4a), age group (Figure 4b), and mathematics identity (Figure 4c).

After running a general linear model incorporating these variables, our main finding was that mathematical media literacy scores correlated positively with mathematics identity (the variable with the largest effect size) such that it overshadowed the effect of high school math level. This is evidenced by a general linear model that explains $25 \%$ of the variance in scores in math knowledge $\left(R^{2}=.253\right.$; Table 4$)$, which indeed improves upon the models that only incorporated high school math levels as an explanatory variable. Interestingly, in this model, high school math did not emerge as a significant explanatory variable at the 0.05 significance threshold, nor did gender, when controlling for all the other explanatory variables; instead, we found mathematics identity explaining $5 \%$ of variance $(p=.002)$, the time participants took to complete the survey $(2.4 \%, p=.002$; Fig. $4 \mathrm{~b})$ and age group (1.6\% explained variance, $p=.009$ ) as statistically significant explanatory variables. For younger respondents, the effect of math identity was more moderate than for older respondents $(p=.012 ; B=-.069)$. In other words, age mitigated the adverse effects of mathematical identity on mathematical media literacy, so that in young adults (18-29), math identity had less of an effect on participants' scores than in older adults (30-70; Fig. 4c). Additionally, high school math levels interacted with gender such that women with no matriculation certificate had lower math scores than would be otherwise expected ( $p=.012 ; B=-.15 ; 1.6 \%$ explained variance; Online Resource 2 ). 


\section{Discussion}

We introduced this paper with the story of the first author explaining her prescient decision to buy masks before the first case was confirmed in Israel. We wondered whether her sensitivity to the news about the pandemic's exponential growth had to do with the fact that she had a strong mathematical identity, including interest in mathematics and a positive attitude towards it. Stemming from this anecdotal incident came the goal of this research - to examine public's interpretations of mathematical information related to the pandemic.

Our first research question referred to the extent to which individuals correctly interpreted COVID-19-related mathematical information featuring in the media. Our findings show that in general, the public correctly interprets some mathematical information, especially if it is given in graphs that include all the relevant information. However, the findings suggest that much of the mathematical information that was presented in the Israeli mass-media during the first weeks of the pandemic was difficult for large parts of the public to comprehend, especially those without advanced school-mathematics education, and specifically when news included discourse around "exponentials," "exponential growth," and the like. This finding recurred whether the question was contextualized or not. By contrast, items based on other contextualized information, such as the "flatten the curve" graph, were relatively easy to interpret by our sample. We suggest that this may be a result of the recurrence of this type of graph in media reports.

Our results, relating to the difficulties our sample encountered with interpreting linear versus exponential growth, are not surprising given that differentiating between these types of growth has been repeatedly shown to be difficult both for students and adults (Ebersbach et al., 2008; Van Dooren et al., 2008; Wagenaar \& Sagaria, 1975). Moreover, these findings strengthen the results of a recent study which showed people generally perform poorly when asked to generate exponential expectations regarding the COVID-19 pandemic (Lammers et al., 2020; Podkul et al., 2020). For example, American participants who were asked to guess the number of coronavirus cases over 5 days in March 2020 showed significant biases in their estimation of exponential growth. In fact, their average estimates could be described as linear: they overestimated the number in the first 3 days and underestimated the last 2 days by $46 \%$.

The lack of understanding of exponential growth has important implications for the ability of the public to assess the daily news about COVID-19. For example, it may lead to people being relatively indifferent to the growth rate during initial phases of the pandemic, when the numbers of added cases per day are still small. Indeed, in the study described earlier (Lammers et al., 2020), those receiving scaffolds for understanding exponential growth were significantly more supportive of social distancing.

Notably, most aspects of mathematical and statistical literacy which have been discussed in previous studies (Coben, 2003; Gal, 2002; PIAAC Numeracy Expert Group, 2009) are taught in compulsory levels of education. Our findings suggest that the relatively low extent to which some adults comprehend exponential growth may derive from restricting the teaching of this subject to advanced levels of mathematical studies. This is supported by the existing body of research regarding public scientific media literacy, which shows that in order to follow science media coverage, members of the public need to independently learn many new science concepts (Laslo \& Baram-Tsabari, 2021; Shea, 2015). This points to re-examination of the place given to exponential growth in math curricula aimed at achieving mathematical literacy.

Our second research question inquired into the relationship between correct interpretations of mathematical data on the news and formal schooling, mathematics identity, and demographic 
variables. Here, our most interesting finding is that participants' mathematics identityincluding the attitudes they developed towards mathematics over the years, what they think of mathematics' usefulness, and how they perceive themselves as learners or doers of mathematics - seems to foreshadow any other variable, including formal schooling. This is a remarkable finding as it hints that for being a mathematically literate citizen, one's mathematics identity may be even more important than the actual mathematics learned in formal settings. The reason for this phenomenon may be that a negative or "weak" mathematical identity (of someone who is "no good" in math) may inhibit people's attending to, processing, or communicating about mathematical information in their daily lives. The rare studies that followed students from school to young adulthood (Boaler \& Selling, 2017) and showed that mathematical identity formed in school impacts the ways young adults engage with mathematics in their daily lives, support this conjecture. However, it certainly needs more corroboration.

Additional variables that were found in our study to be important for explaining the proportion of correct answers on the math in the media questionnaire were age and the time spent on the test. However, the correlation between time and correct answers was quite low and can be explained in many ways: it may be the case that participants who gave the survey more attention achieved better results; alternatively, it may be that participants with low knowledge of mathematics used less time because they guessed the answers and this took less time than using correct procedures. In this context, it is important to remember that the test was taken as a survey in which people had very little incentive to "do well" (unlike institutionalized exams, perhaps).

The age variable is more interesting, and especially the interaction it had with math identity. We found that, in general, young adults (18-29) scored higher than older adults (30-70). This result may be related to young adults having fresher memories of highschool mathematics, as knowledge exists on a use-it or lose-it basis. Alternatively, this result could be explained by increased access to educational opportunities over time. It is also consistent with the PIAAC results for Jewish Israeli adults, whose peak scores are in the age groups of 25-29 and 30-34 (both 276), while older age groups score lower and lower, to the point of 234 and 236 in age groups of 55-59 and 60-65, respectively (Israel Central Bureau of Statistics and National Authority for Measurement and Evaluation in Education, 2016, p. 159). Additionally, in our sample, in young adults (18-29), affective aspects (math identity) had less of an effect on scores of mathematical media literacy than in older adults. This finding may mean that mathematical identity becomes of increasing importance as one's age progresses and one's knowledge becomes more dependent on life experiences, professional knowledge, etc.

In addition to the methodological limitations that were mentioned in the methods section, we should hedge our conclusions by acknowledging that the mathematical content we examined in this study related only to the content that was accessible to us through public media during the first months of the pandemic. Also, the situation, both with relation to what was presented in the news, and with relation to the public's mathematical competencies, may be different in other countries.

The above limitations also relate to the relative "youth" of the field of public understanding of mathematics as compared with public understanding of science. We thus have limited opportunities to compare our findings to previous research. Although research has been done on how lay people interpret mathematical information when faced with a personal health hazard or decisions (e.g., Ancker \& Kaufman, 2007), rarely have studies examined mathematical media literacy. Our findings do connect, however, to research on the scientific aspects 
of public engagement with COVID-19, which found correlations of science knowledge (operationalized as level of science education achieved in school/university) and understanding the science underlying COVID-19 (Baram-Tsabari et al., 2021; Taragin-Zeller et al., 2020).

\section{Conclusions}

One of the main reasons for making mathematics a compulsory subject to all students - not just those who will continue to take more advanced math - is to provide these individuals with the knowledge and skills which may help them to cope with exactly such a scenario as the necessity to interpret mathematical information during a world-wide pandemic. However, the ability of participants who took only compulsory level math to interpret the mathematical aspects of news around COVID-19 was quite low. This raises serious doubt regarding our participants' ability to be critical consumers of such news at a time when it is most relevant to directing their behavior.

The findings also suggest that mathematics identity may support or constrain an individuals' ability to reason with and about numeric data appearing in the media, even when controlling for educational attainment in mathematics. It may be the case that negative/weak mathematics identity hinders performance on these tasks, but why this happens requires further investigation.

In many ways, the COVID-19 pandemic brought us a unique, perhaps unprecedented, opportunity to study how the public engages with numbers "in the wild" (Chinn \& Golan Duncan, 2018). This study, we believe, shows that there is certainly room for improvement in this respect. We believe this has consequences for the media, which needs to consider the strengths and weaknesses of the public in understanding mathematical information. However, more importantly, our findings should trigger some soul-searching in the mathematics education field. After all, if school mathematics does not prepare its graduates to engage with the mathematics that surrounds them in everyday life, what good does it serve for the vast majority of the population?

Supplementary Information The online version contains supplementary material available at https://doi.org/ 10.1007/s10649-021-10075-8.

Acknowledgements This study was partially supported by the Israel Science Foundation grant no. 2699/17.

\section{References}

Aiken, L. R., \& Dreger, R. M. (1961). The effect of attitudes on performance in mathematics. Journal of Educational Psychology, 52(1), 19-24. https://doi.org/10.1037/h0041309

Ancker, J. S., \& Kaufman, D. (2007). Rethinking health numeracy: A multidisciplinary literature reviews. Journal of the American Medical Informatics Association, 14(6), 713-721. https://doi.org/10.1197/jamia. M2464.Introduction

Ancker, J. S., Senathirajah, Y., Kukafka, R., \& Starren, J. B. (2006). Design Features of Graphs in Health Risk Communication: A Systematic Review. Journal of the American Medical Informatics Association, 13(6), 608-618. https://doi.org/10.1197/jamia.M2115

Baram-Tsabari, A., Bronshtein, J., Rozenblum, Y., Barel-Ben David, Y., \& Swirski, H. (2021). Sports fans' science knowledge is relevant to their stance on COVID-19 guidelines, but only if they don't care who wins Paper presented at the Public Communication of Science and Technology (PCST) 2020+1 Conference. Aberdeen. 
Bishop, J. P. (2012). "She's Always Been the Smart One. I’ve Always Been the Dumb One": Identities in the Mathematics Classroom. Journal for Research in Mathematics Education, 43(1), 34-74. https://doi.org/10. 5951/jresematheduc.43.1.0034

Boaler, J., \& Selling, S. K. (2017). Psychological Imprisonment or Intellectual Freedom? A Longitudinal Study of Contrasting School Mathematics Approaches and Their Impact on Adults' Lives. Journal for Research in Mathematics Education, 48(1), 78-105. https://doi.org/10.5951/jresematheduc.48.1.0078

Chinn, C., \& Golan Duncan, R. (2018). What is the value of general knowledge of scientific reasoning? In F. Fischer, C. Chinn, K. Engelmann, \& J. Osborne (Eds.), Scientific Reasoning and Argumentation (pp. 77101). Routledge. https://doi.org/10.1136/bmj.4.5843.791-b

Coben, D. (2003). Adult numeracy: Review of research and related literature. National Research and Development Centre for adult literacy and numeracy Retrieved from http://www.nrdc.org.uk/uploads/ documents/doc_2802.pdf

Darragh, L. (2016). Identity research in mathematics education. Educational Studies in Mathematics, 93(1), 1933. https://doi.org/10.1007/s10649-016-9696-5

De Bock, D., Verschaffel, L., \& Janssens, D. (1998). The predominance of the linear model in secondary school students' solutions of word problems involving length and area of similar plane figures. Educational Studies in Mathematics, 35, 65-83. https://doi.org/10.1023/A:1003151011999

Dowker, A., Bennett, K., \& Smith, L. (2012). Attitudes to mathematics in primary school children. Child Development Research, 2012, 1-8. https://doi.org/10.1155/2012/124939

Ebersbach, M., Lehner, M., Resing, W. C. M., \& Wilkening, F. (2008). Forecasting exponential growth and exponential decline: Similarities and differences. Acta Psychologica, 127(2), 247-257. https://doi.org/10. 1016/j.actpsy.2007.05.005

Ehmke, T., Wild, E., \& Müller-Kalhoff, T. (2005). Comparing adult mathematical literacy with PISA students: Results of a pilot study. ZDM-Mathematics Education, 37(3), 159-167. https://doi.org/10.1007/s11858-0050005-5

Evans, J. (2000). Adults' Mathematical Thinking and Emotions. Studies in Mathematics Education Series. RoutledgeFalmer.

Fives, H., Huebner, W., Birnbaum, A. S., \& Nicolich, M. (2014). Developing a measure of scientific literacy for middle school students. Science Education, 98(4), 549-580. https://doi.org/10.1002/sce.21115

Gal, I. (2002). Adults ' statistical literacy: Meanings, components, responsibilities. International Statistical Review, 70(1), 1-51

PIAAC Numeracy Expert Group (2009), PIAAC Numeracy: A Conceptual Framework. OECD Education Working Papers, No. 35. OECD Publishing. https://doi.org/10.1787/220337421165

Gal, I., Grotlüschen, A., Tout, D., \& Kaiser, G. (2020). Numeracy, adult education, and vulnerable adults: A critical view of a neglected field. ZDM-Mathematics Education, 52(3), 377-394. https://doi.org/10.1007/ s11858-020-01155-9

Golbeck, A. L., Ahlers-Schmidt, C. R., Paschal, A. M., \& Dismuke, S. E. (2005). A definition and operational framework for health numeracy. American Journal of Preventive Medicine, 29(4), 375-376. https://doi.org/ 10.1016/j.amepre.2005.06.012

Graven, M., \& Heyd-Metzuyanim, E. (2019). Mathematics identity research: The state of the art and future directions: Review and introduction to ZDM Special Issue on Identity in Mathematics Education. ZDMMathematics Education, 51(3), 361-377. https://doi.org/10.1007/s11858-019-01050-y

Gyllenhaal, E. D. (2006). Memories of math: Visitors' experiences in an exhibiton about calculus. Curator: The Museum Journal, 49(3), 345-364. https://doi.org/10.1111/j.2151-6952.2006.tb00228.x

Heyd-Metzuyanim, E. (2015). Vicious cycles of identifying and mathematizing: A case study of the development of mathematical failure. Journal of the Learning Sciences, 24(4), 504-549. https://doi.org/10.1080/ 10508406.2014.999270

Israel Central Bureau of Statistics and National Authority for Measurement and Evaluation in Education (2016). Meyumanuyot Bogrim BeYisra'el 2014-2015 [Adult Skills in Israel 2014-2015]. Publication no. 1640. Author. https://meyda.education.gov.il/files/Rama/PIAAC_Report.pdf

Jarman, R., \& McClune, B. (2007). Developing scientific literacy: Using news media in the classroom. McGrawHill International.

Johnston-Wilder, S., Brindley, J., \& Dent, P. (2014). A survey of mathematics anxiety and mathematical resilience among existing apprentices. The Gatsby Charitable Foundation.

Kalliauer, J. (2020). COVID-19 Health care limit-Spatial/Social distancing delays the further spread of a virus and preserves the capacity of the health system. Wikimedia Commons. https://commons.wikimedia.org/ wiki/File:COVID-19_Health_care_limit.svg

Karsenty, R. (2002). What do adults remember from their high school mathematics? The case of linear functions. Educational Studies in Mathematics, 51(1/2), 117-144. https://doi.org/10.1023/A:1022429504802 
Karsenty, R. (2004). Mathematical self-schema: A framework for analyzing adults' retrospection on high school mathematics. The Journal of Mathematical Behavior, 23(3), 325-349. https://doi.org/10.1016/j.jmathb. 2004.06.004

Lammers, J., Crusius, J., \& Gast, A. (2020). Correcting misperceptions of exponential coronavirus growth increases support for social distancing. Proceedings of the National Academy of Sciences, 117(28), 16264 16266.

Laslo, E., \& Baram-Tsabari, A. (2021). Expressions of science literacy in online public discussions of animal experimentation. International Journal of Science Education, Part B, 11(1), 55-74. https://doi.org/10.1080/ 21548455.2020.1871103

Ma, X., \& Kishor, N. (1997). Attitude toward self, social factors, and achievement in mathematics. Educational Psychology Review, 9(2), 89-120 Retrieved from https://link.springer.com/article/10.1023/A\% 3A1024785812050

Maaß, J., \& Schlöglmann, W. (2000). Erwachsene und Mathematik. Mathematica Didactica. Zeitschrift Für Didaktik Der Mathematik, 23(2), 95-106.

Maffia, A., \& Marrioti, M. A. (2018). Adults' conception of multiplication: Effects of schooling on multiplicative conceptual field. In K. Safford-Ramus, J. Maaß, \& E. Süss-Stepancik (Eds.), Contemporary research in adult and lifelong learning of mathematics (pp. 95-108). ICME-13 Monographs, Springer. https://doi.org/ 10.1007/978-3-319-96502-4

McClune, B., \& Jarman, R. (2010). Critical reading of science-based news reports: Establishing a knowledge, skills and attitudes framework. International Journal of Science Education, 32(6), 727-752. https://doi.org/ 10.1080/09500690902777402

McLeod, D. B. (1992). Research on affect in mathematics education: A reconceptualization. In D. A. Grouws (Ed.), Handbook of research on mathematics teaching and learning (pp. 575-596). Macmillan Publishing Company.

Mullis, I. V. S., \& Martin, M. O. (Eds.). (2017). TIMSS 2019 Assessment Frameworks. Retrieved from Boston College, TIMSS \& PIRLS International Study Center website: http:/timssandpirls.bc.edu/timss2019/ frameworks/

Niss, M. (1996). Goals of Mathematics Teaching. In A. J. Bishop, M. A. K. Clements, K. Clements, C. Keitel, J. Kilpatrick, \& C. Laborde (Eds.), International Handbook of Mathematics Education (pp. 11-47). Springer Netherlands.

Nordheim, L. V., Pettersen, K. S., Espehaug, B., Flottorp, S. A., \& Guttersrud, Ø. (2019). Lower secondary school students' scientific literacy and their proficiency in identifying and appraising health claims in news media: A secondary analysis using large-scale survey data. BMJ Open, 9(10), e028781. https://doi.org/10. 1136/bmjopen-2018-028781

OECD. (2016). Skills matter: Further results from the survey of adult skills. OECD skills studies. OECD Publishing. https://doi.org/10.1787/9789264258051-9-en

OECD. (2019). The survey of adult skills: Reader's companion. In OECD skills studies (3rd ed.). OECD Publishing. https://doi.org/10.1787/f70238c7-en.

Podkul, A., Vittert, L., Tranter, S., \& Alduncin, A. (2020). The Coronavirus Exponential: A Preliminary Investigation into the Public's Understanding. Harvard Data Science Review. https://doi.org/10.1162/ 99608f92.fec69745

Reid, G., \& Norris, S. P. (2016). Scientific media education in the classroom and beyond: A research agenda for the next decade. Cultural Studies of Science Education, 11(1), 147-166. https://doi.org/10.1007/s11422015-9709-1

Roberts, D. A., \& Bybee, R. W. (2014). Scientific literacy, science literacy, and science education. In N. G. Lederman \& S. K. Abell (Eds.), Handbook of Research on Science Education (II ed., pp. 545-558). Routledge.

Schwartz, L. M., Woloshin, S., Black, W. C., \& Welch, H. G. (1997). The role of numeracy in understanding the benefit of screening mammography. Annals of Internal Medicine, 127(11), 966-972. https://doi.org/10. 7326/0003-4819-127-11-199712010-00003

Sfard, A., \& Prusak, A. (2005). Telling Identities: In Search of an Analytic Tool for Investigating Learning as a Culturally Shaped Activity. Educational Researcher, 34(4), 14-22. https://doi.org/10.3102/ 0013189X034004014

Shauli, S., \& Baram-Tsabari, A. (2019). The usefulness of science knowledge for parents of hearing-impaired children. Public Understanding of Science, 28(1), 19-37. https://doi.org/10.1177/0963662518772503

Shea, N. A. (2015). Examining the nexus of science communication and science education: A content analysis of genetics news articles. Journal of Research in Science Teaching, 52(3), 397-409. https://doi.org/10.1002/ tea. 21193

Taragin-Zeller, L., Rozenblum, Y., \& Baram-Tsabari, A. (2020). Public engagement with Science among Religious Minorities: Lessons from Covid-19 Science Communication. SAGE Journals, 42(5), 643-678. 
Tseng, A. S. (2018). Students and evaluation of web-based misinformation about vaccination: Critical reading or passive acceptance of claims? International Journal of Science Education, Part B: Communication and Public Engagement, 8(3), 250-265. https://doi.org/10.1080/21548455.2018.1479800

Van Dooren, W., De Bock, D., Janssens, D., \& Verschaffel, L. (2008). The linear imperative: An inventory and conceptual analysis of students' overuse of linearity. Journal for Research in Mathematics Education, 39(3), 311-342.

Wagenaar, W. A., \& Sagaria, S. D. (1975). Misperception of exponential growth. Perception \& Psychophysics, 18(6), 416-422. https://doi.org/10.3758/BF03204114

Wedege, T., \& Evans, J. (2006). Adults' resistance to learning in school versus adults' competences in work: The case of mathematics. Adults Learning Mathematics, 1(2), 28-43.

Weeth Feinstein, N. (2014). Making sense of autism: Progressive engagement with science among parents of young, recently diagnosed autistic children. Public Understanding of Science, 23(5), 592-609.

Publisher's note Springer Nature remains neutral with regard to jurisdictional claims in published maps and institutional affiliations. 